\title{
Coulisses
}

Revue de théâtre

19 | Hiver 1999

Varia

\section{La Riposte des exclus}

Centre d'Art et de Plaisanterie, Montbéliard - Novembre 1998

\section{Guy Barbier}

\section{OpenEdition}

\section{Journals}

Édition électronique

URL : https://journals.openedition.org/coulisses/5461

DOI : $10.4000 /$ coulisses.5461

ISSN : 2546-9460

Éditeur

Presses universitaires de Franche-Comté

\section{Édition imprimée}

Date de publication : 1 janvier 1999

Pagination : 22

ISBN : 2-913322-09-3

ISSN : $1150-594 X$

\section{Référence électronique}

Guy Barbier, "La Riposte des exclus », Coulisses [En ligne], 19| Hiver 1999, mis en ligne le 18 octobre 2019, consulté le 12 janvier 2022. URL : http://journals.openedition.org/coulisses/5461 ; DOI : https:// doi.org/10.4000/coulisses.5461

Ce document a été généré automatiquement le 12 janvier 2022.

Coulisses 


\title{
La Riposte des exclus
}

\author{
Centre d'Art et de Plaisanterie, Montbéliard - Novembre 1998
}

\section{Guy Barbier}

$1 \quad$ Et de quatre! Pour le plus grand bonheur des spectateurs de plus en plus nombreux au fil des ans. Le théatre était complet pour Fellag, plein à craquer pour le championnat de hip hop et bourré pour L'Migri de Mohamed Guellati. Public bigarré, chaleureux. Une vraie réussite pour le brassage multiculturel, qui une fois encore n'est pas une expression creuse.

2 Ombre au tableau, L'Écumeur ou les cavaliers bannis d'Aphra Behn (1640-1688), mise en scène par Christine Dejoux n'a pas reçu du ministère de la Justice l'autorisation d'être présentée à Montbéliard. Raisons de sécurité: le caractère vindicatif des Montbéliardais a sans doute effrayé le ministère qui craignait pour la sécurité des acteurs, tous détenus ou ex-détenus, malgré la présence policière prévue dans le public pour prévenir tous les débordements. Quel dommage!

3 Mais malgré cette absence cruelle qui prive de parole les détenus, exclus parmi les exclus, le pari du CAP est gagné. « Nous avons remarqué que le meilleur art pousse sur des terres de souffrances", dit Jacques Livchine, son co-directeur, qui parle franc dans les colonnes du numéro de septembre d'Atmosphère ${ }^{1}$. Et il ajoute : «Nous souhaiterions beaucoup qu'un maximum de personnes viennent assister à nos spectacles : ainsi, ils verraient le bon côté de l'immigration. » Nous sommes venus, nous avons vu et nous avons été terrassés de plaisir. Il était d'ailleurs cocasse de voir la gêne et le plaisir circuler simultanément dans le public.

4 C'était flagrant avec Djurdjurassique Bled de et par Fellag, un spectacle décapant, corrosif, acide, sans concession aucune si ce n'est sur le sexe puisqu'il n'y a que des problèmes « textuels » en Algérie. Les rires fusent dans la salle, pas aux mêmes endroits selon que le texte moque les Français, les Berbères, les Arabes, les croyants, les Suisses... Y a-t-il meilleure arme que l'humour pour combattre la bêtise et la cruauté ? Sans doute pas quand l'horreur des massacres continue inlassablement, comme si Fellag avait raison : « Nous les Algériens, on va couler l'Algérie. » Du théâtre populaire, sans artifice, pour un public enthousiaste qui lance des « youyous ». Et un rappel à la fin 
à propos de censure nationale et familiale (toujours un problème de texte). Un vrai régal. ${ }^{2}$

Avec L'Migri', nous avons droit à une leçon d'histoire comme on aimerait en avoir tous les jours. Un pan entier de notre histoire de France, quand celle-ci faisait le grand écart par-dessus la Méditerranée, quand Oran, Constantine étaient départements français.

1953 : une France coloniale, méprisante, paternaliste, où les droits sociaux n'étaient pas les mêmes selon que l'on venait du sud ou du nord; une France coloniale qui recrute ses enfants pour l'effort de guerre : 400.000 en 1914-18, 200.000 en 1939-40, 70.000 pour l'Indochine.

71975 : Momo au Paradis ; un beau titre, une réalité cruelle : les marches, le videur, le caissier qui dit NON!, l'humiliation, toutes les injures de la terre proférées sur le parking, en attendant Riton qui a les clés de la bagnole. L'Migri, un homme de dos, une voix off qui dit avec des mots simples la réalité du voyage, l'envers du rêve : fouille, corruption, passeport, masturbation, métro, boulot... Le retour au pays, le décalage, la femme kabyle, les youyous, la fête, le mariage, les traditions, le refus du fils qui, le père étant mort, se retrouve chef de famille. Aujourd'hui, l'avenir appartient aux enfants, leur histoire est à inventer, à rêver, même si c'est difficile. La dernière image, une femme en croix au sol. La lumière qui faiblit. Plus de questions que de réponses: questions d'identité, avec la carte (d'identité) française affichée sur la porte au risque de passer pour une cinglée auprès des voisins. Signe distinctif: néant. C'est toute l'histoire de cette identité double, douloureuse, qui se forge avec le temps, avec ces musiques très présentes, vieillottes, traditionnelles ou actuelles. Une force du mélange qui nous imprègne.

8 Aujourd'hui : c'est encore le vocabulaire raciste, xénophobe, sournois, franc ou pas ; c'est toutes les appréhensions, les peurs du Français "de souche", de sa femme hystérique qui le pousse, con-génitale comme c'est pas permis; c'est toute une partie de la France bête et méchante, caricaturée pour la scène, même si la réalité dépasse parfois la caricature. Cette scène très comique me met mal à l'aise et ne me fait pas beaucoup rire. Ceux qui rient le plus sont ceux qui se sentent le moins de parenté avec ce couple de Français moyens. J'aimerais ne jamais être ce con-génital, même l'instant fugace d'une pensée.

9 Le championnat de hip hop fut une belle fête un peu improvisée, une belle joute moderne où les règles étaient presque respectées. Une énergie et des prouesses techniques à couper le souffle, comme ce strip-tease amorcé sur la tête en tournant comme une toupie. L'audace et l'inventivité ne semblent pas avoir de limites.

10 Mais le moment le plus fort de cette soirée fut sans conteste la prestation du groupe strasbourgeois Magic Electro. Un spectacle rond à la chorégraphie impeccable, soignée, pleine de sens. Une concentration et une réelle présence de tous les acteurs/danseurs. De l'émotion, de vraies entrées, de vraies sorties, même s'il fallait passer à travers les autres acteurs qui s'étalaient sur le côté. On peut parier que les groupes de l'Aire Urbaine en auront pris de la graine. Le hip hop est affaire de performance, de défi, d'explosion des corps et d'apesanteur, mais ce peut être aussi un spectacle d'une grande force, qui égale et parfois surpasse celle du verbe. 


\section{NOTES}

1. Le magazine culturel de l'Aire Urbaine.

2. Le spectacle intégral figure sur le double CD de BA Productions, référence PP9801, diffusé par Nomad.

3. Voir Coulisses $n^{\circ}$ 17, p. 13, pour le compte rendu de ce spectacle lors de son passage à Besançon.

\section{AUTEURS}

GUY BARBIER

TUFC 